\title{
Association Between Health Behaviors and Family History of Cancer in Cancer Survivors: Data From the Korean Genome and Epidemiology Study
}

\author{
Minji Hwang ${ }^{1}$, Boyoung Park ${ }^{2,3}$ \\ ${ }^{1}$ Center for Breast Cancer, Hospital, National Cancer Center, ${ }^{2}$ Department of Cancer Control and Population Health, National Cancer Center \\ Graduate School of Cancer Science and Policy, ${ }^{3}$ National Cancer Control Institute, National Cancer Center, Goyang, Korea
}

\begin{abstract}
Background: We compared health behaviors, including current smoking, alcohol drinking, regular exercise, obesity, and abdominal obesity, among Korean cancer survivors with and without family history of cancer.

Methods: This study included 5,247 cancer survivors with family history of cancer (1,894 with and 3,353 without), who were recruited from the Health Examinee cohort. Health behaviors were identified using questionnaire. Adjusted ORs (aORs) between health behaviors and family history of cancer were estimated by multivariate logistic regression analysis adjusted for sociodemographic factors. All analyses were conducted separately according to sex.

Results: Prevalence of current smoking, alcohol drinking, no regular exercise, obesity, and abdominal obesity was $16.3 \%, 48.3 \%, 36.0 \%$, $31.3 \%$, and $42.3 \%$ in male cancer survivors and $1.7 \%, 20.6 \%, 43.8 \%, 28.5 \%$, and $72.5 \%$ in female, respectively. Health behaviors in male cancer survivors with and without family history of cancer were not significantly different after being adjusted for other covariates $(\mathrm{aOR}=1.04,95 \% \mathrm{Cl}=0.75-1.44$ for current smoking; $\mathrm{aOR}=0.96,95 \% \mathrm{Cl}=0.76-1.22$ for current drinking; $\mathrm{aOR}=0.85,95 \% \mathrm{Cl}=$ 0.66-1.10 for regular exercise; $\mathrm{aOR}=0.96,95 \% \mathrm{Cl}=0.73-1.25$ for obesity; $\mathrm{aOR}=0.97,95 \% \mathrm{Cl}=0.75-1.25$ for abdominal obesity). In female cancer survivors, there were no significant differences in health behaviors according to family history of cancer (aOR $=0.76$, $95 \% \mathrm{Cl}=0.44-1.32 ; \mathrm{aOR}=1.11,95 \% \mathrm{Cl}=0.94-1.31 ; \mathrm{aOR}=0.99,95 \% \mathrm{Cl}=0.87-1.14 ; \mathrm{aOR}=0.99,95 \% \mathrm{Cl}=0.85-1.16 ; \mathrm{aOR}=$ $0.93,95 \% \mathrm{Cl}=0.80-1.10$, respectively).

Conclusions: We identified no significant differences in health behaviors according to family history of cancer in cancer survivors. More studies should be conducted to identify correlations between family history of cancer and prognosis in cancer survivors.
\end{abstract}

(J Cancer Prev 2017;22:166-173)

Key Words: Cancer survivor, Family cancer history, Health behavior

\section{INTRODUCTION}

Cancer is one of the important health burdens in Korea since 1983. A total of 217,057 new cancer patients and 76,611 deaths were recorded in 2014. As the 5-year relative cancer survival rate has improved from $41.2 \%$ in 1993 to 1995 to $70.3 \%$ in 2010 to 2014, the number of long-term cancer survivors has increased rapidly, with 806,780 5-year cancer survivors in 2014. ${ }^{1}$

Among cancer survivors, the risks of other health problems, including short- and long-term side effects of treatment, recurrence, other comorbidities, and decline in functioning, are increased, ${ }^{2-4}$ and health behavior is important to reduce the risk of recurrence and decrease the adverse effects of cancer therapy. ${ }^{5-7}$ Studies have shown that smoking cessation after the diagnosis of early stage lung cancer delayed the progression and was beneficial for health. ${ }^{8}$ Thus, compared with the general population, tertiary prevention through having healthy lifestyle habits is important for cancer survivors, followed by increased

Received August 31, 2017, Accepted September 3, 2017

Correspondence to: Boyoung Park

Department of Cancer Control and Population Health, National Cancer Center Graduate School of Cancer Science and Policy, 323 Ilsan-ro, Ilsandong-gu, Goyang 10408, Korea

Tel: +82-31-920-2914, Fax: +82-31-920-2759, E-mail: hayejine@ncc.re.kr, ORCID: Boyoung Park, http://orcid.org/0000-0003-1902-3184

Copyright (C) 2017 Korean Society of Cancer Prevention

(c) This is an Open Access article distributed under the terms of the Creative Commons Attribution Non-Commercial License (http://creativecommons.org/licenses/by-nc/4.0) which permits unrestricted non-commercial use, distribution, and reproduction in any medium, provided the original work is properly cited. 
attention to smoking, drinking, and physical activity. ${ }^{9-11}$

Family history of cancer (FHCA) is one of the non-modifiable risk factors of cancer and has been suggested to affect prognosis of cancer survivors. Studies showed that FHCA improved survival in head and neck, ${ }^{12}$ gastric, ${ }^{13}$ and colorectal cancer patients, ${ }^{14,15}$ but no association between family history and breast cancer survival was observed. ${ }^{16-18}$ In some studies, better survival in cancer survivors was correlated to surveillance monitoring and health behaviors; ${ }^{13,15}$ another study showed that he/she performed more surveillance behaviors influencing their cancer risk when someone knew that he/she had an FHCA. ${ }^{19}$ Thus, in cancer survivors where healthy lifestyle behaviors are more important for better survival and life quality, comparison of health behaviors according to FHCA would help explain the increased survival.

This study aimed to investigate and compare health behaviors, including smoking, alcohol drinking, regular exercise, obesity, and abdominal obesity, in cancer survivors with or without FHCA.

\section{MATERIALS AND METHODS}

\section{Study population}

We analyzed data from the Korean Genome and Epidemiology Study (KoGES) conducted by the National Research Institute of Health and Centers for Disease Control and Prevention, which aimed to develop comprehensive health care guidelines and reduce chronic diseases in Koreans. ${ }^{20}$ KoGES was classified into six types of cohorts, and this study used baseline data of the Health Examinee (HEXA) cohort, which consists of participants aged 40 to 79 years who were recruited between 2004 and 2013. Participants were invited to health examination centers in eight regions (metropolitan areas or major cities) in Korea. After obtaining informed consent, a survey using standardized questionnaire was conducted by trained research staff. ${ }^{21}$ The questionnaire included sociodemographic characteristics, personal medical history, family medical history, medication usage, lifestyle behaviors (smoking, dietary habits, alcohol drinking, and physical activity), and reproductive factors. Details of the KoGES and HEXA study have been described elsewhere (http://www.nih.go.kr/NIH/eng/ main.jsp).

With a total of 173,357 subjects in the HEXA cohort, we first selected 5,274 participants who responded that they had never been diagnosed with cancer by a physician. Then, 27 participants who had missing information on questions of FHCA were excluded. The remaining 5,247 participants had an FHCA (Fig. 1). The Institutional Review Board of the National Cancer Center approved the study protocol (approval no. NCC2014-0098).

\section{Variables}

FHCA was defined as positive family history of any type of cancer in participants' first-degree relatives, including parents,

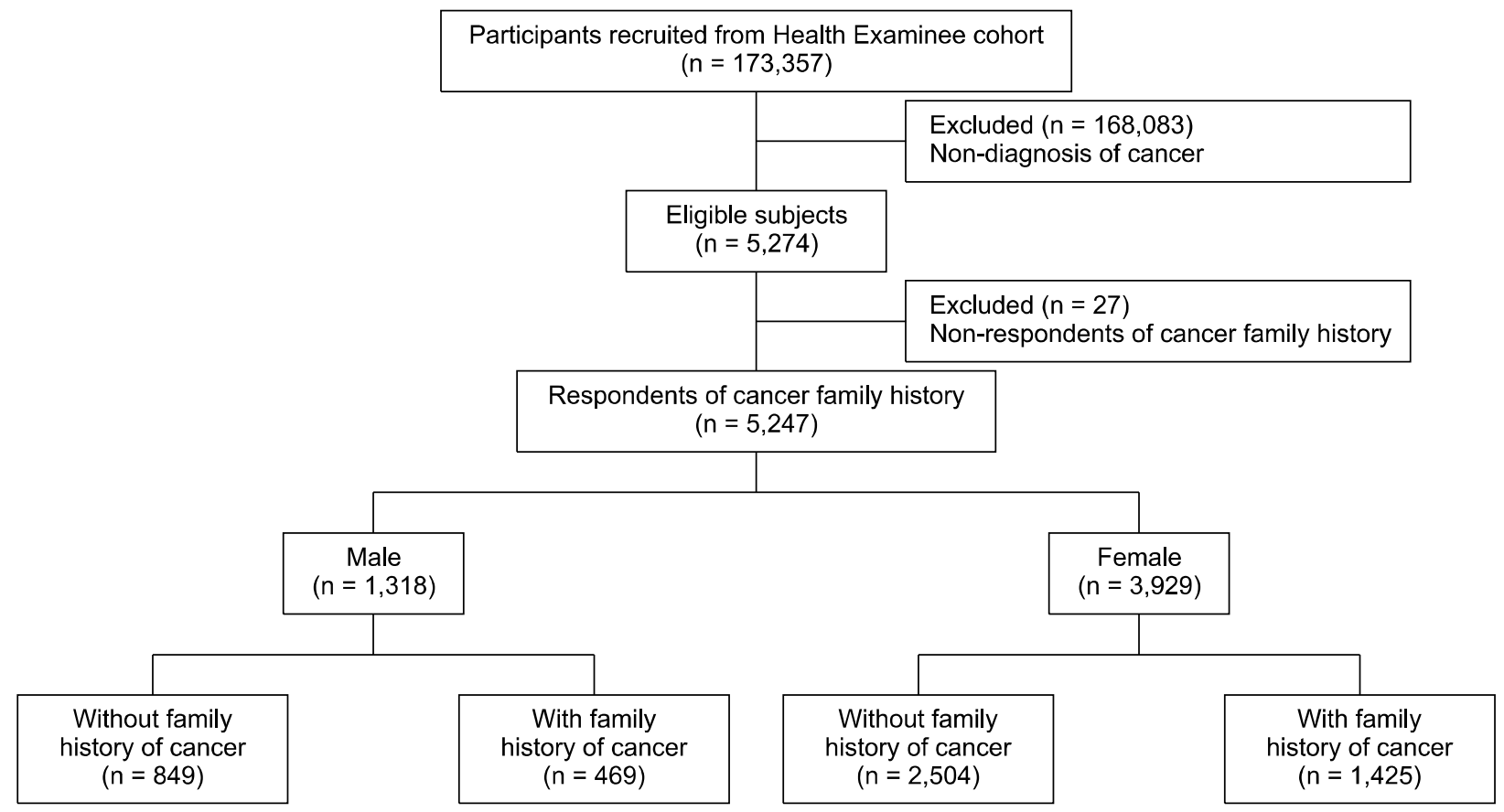

Figure 1. Selection of study population. 
siblings, or children. The outcomes of this study included current smoking, current alcohol drinking, regular exercise, obesity, and abdominal obesity at the time of survey. Current smokers were defined as those who had smoked $\geq 100$ cigarettes in their life time and still smoked at the time of survey. Current alcohol drinkers were defined as those who reported that they were current drinkers at the time of survey. Regular exercise was defined as performing regular exercise enough to sweat once a week or more. Body mass index (BMI) was used as an index for obesity and calculated using height and weight. Participants with BMI $\geq 25 \mathrm{~kg} / \mathrm{m}^{2}$ were considered obese. ${ }^{22}$ Waist-hip ratio (WHR), which reflects abdominal obesity, was calculated, and women and men with WHR $\geq 0.80$ and $\geq 0.90$, respectively, were considered as having abdominal obesity. ${ }^{23}$

Other considered covariates included age (40-49/50-59/ $\geq 60$ years), education (below high school/high school diploma/collegiate level), household income ( $<1,500,000 / 1,500,000-2,999,999 / 3,000,000$ 3,999,999/ $\geq 4,000,000 \mathrm{KRW}$ ), employment condition (yes/no), any chronic disease in the past diagnosed by a physician (yes/no), and self-rated health (healthy/normal/unhealthy). In case of women, numbers of children (0/1-2/3-4/ $\geq 5)$ and menopause (yes/no) were included.

\section{Statistical analysis}

All analyses were conducted separately according to sex. The chi-square test was used to assess whether there were differences

Table 1. Characteristics according to FHCA in males and females diagnosed with cancer (KoGES 2004-2013)

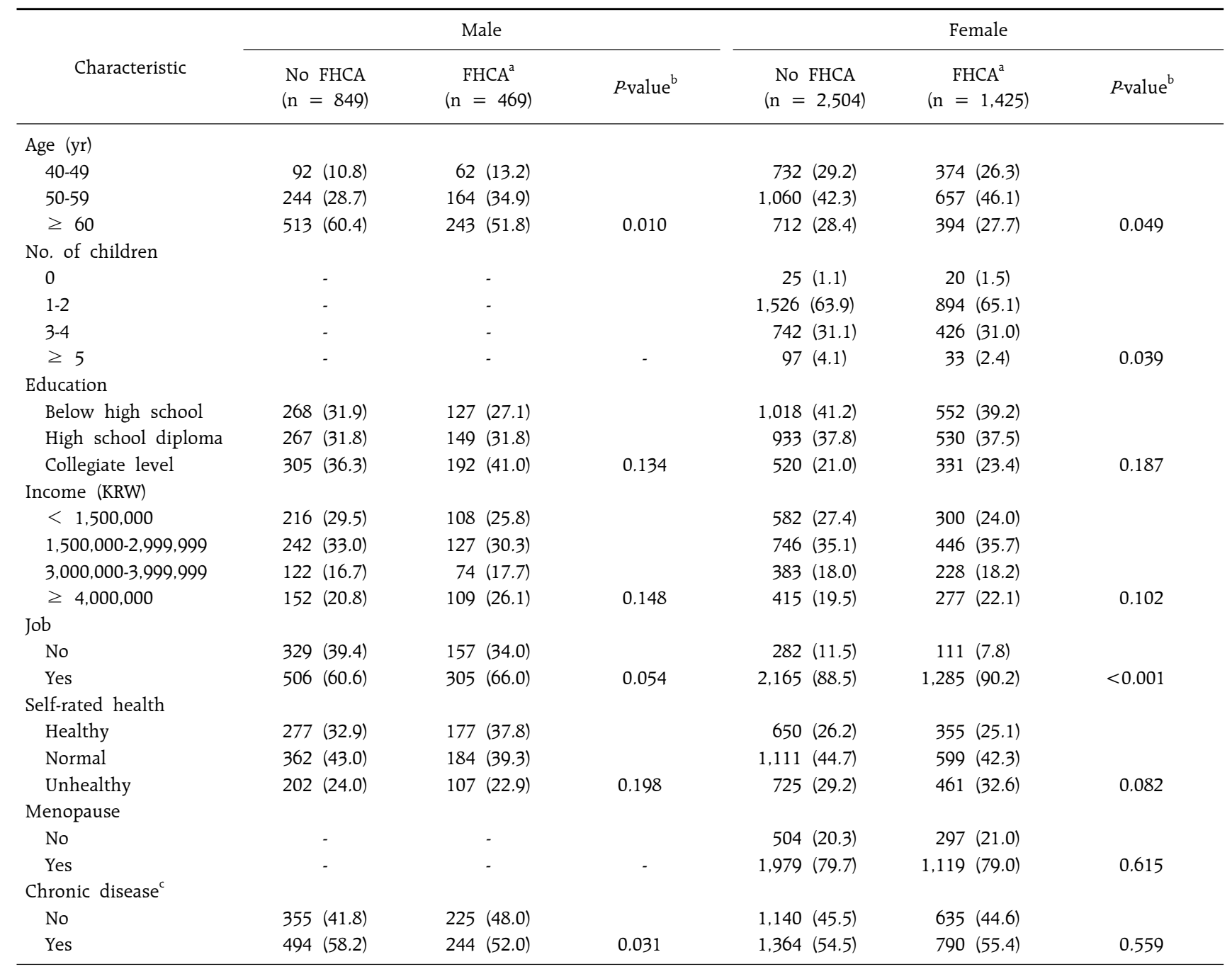

Values are presented as number (\%). FHCA, family history of cancer; KoGES, Korean Genome and Epidemiology Study. ${ }^{\mathrm{F}} \mathrm{FHCA}$ included a family history of any type of cancer. ${ }^{b} P$-values were determined using chi-square excluding the missing data. ${ }^{\mathrm{c} C h r o n i c}$ diseases included the diagnosis of any kind of chronic disease by a physician in the past. 
in sociodemographic characteristics among cancer survivors with and without FHCA. The proportion of current smoking, drinking, regular exercise, obesity, and abdominal obesity among cancer survivors with and without FHCA was compared using chi-square as well. We used multivariate logistic regression to assess independent associations between health behaviors and FHCA in cancer survivors, adjusting for age, education, monthly household income, job status, self-rated health, and chronic disease. In case of women, menopause and number of children were additionally included as covariates. The results were presented as adjusted OR (aOR) and 95\% CIs. To evaluate the clustering effects of health behaviors, multivariate logistic regression was performed, clustering health behaviors after being adjusted for covariates. All statistical analyses were performed with SAS software ver. 9.3 (SAS Institute, Cary, NC, USA).

\section{RESULTS}

\section{Characteristics of cancer survivors according to family history of cancer}

The baseline sociodemographic characteristics by family history in male and female cancer survivors are shown in Table 1. Of 1,318 male cancer survivors, 469 had an FHCA. Of 3,929 female cancer survivors, 1,425 had an FHCA. Of the male cancer survivors, age distribution and chronic disease status were significantly different according to FHCA. Of the female cancer survivors, age distribution, number of children, and job status were significantly different according to FHCA, suggesting minimally different distribution of baseline characteristics in cancer survivors according to family history.

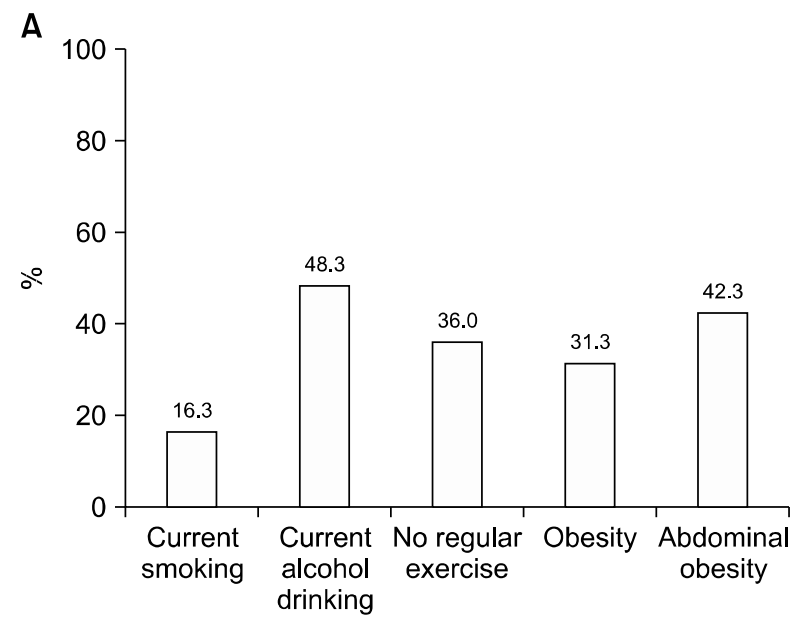

\section{Health behaviors in cancer survivors}

The prevalence of current smoking, alcohol drinking, no regular exercise, obesity, and abdominal obesity was $16.3 \%$, $48.3 \%, 36.0 \%, 31.3 \%$, and $42.3 \%$ in male cancer survivors (Fig. 2A) and $1.7 \%, 20.6 \%, 43.8 \%, 28.5 \%$, and $72.5 \%$ in female cancer survivors, respectively (Fig. 2B). The comparison of lifestyle factors according to FHCA in male and female survivors did not show significant differences (Table 2).

Health behaviors, including current smoking, current drinking, regular exercise, obesity, and abdominal obesity in male cancer survivors with FHCA, were not significantly different compared with those without FHCA after being adjusted for other covariates $(\mathrm{aOR}=1.04,95 \% \mathrm{CI}=0.75-1.44 ; \mathrm{aOR}=0.96,95 \% \mathrm{CI}=$ $0.76-1.22 ; \mathrm{aOR}=0.85,95 \% \mathrm{CI}=0.66-1.10 ; \mathrm{aOR}=0.96,95 \% \mathrm{CI}=$ $0.73-1.25 ;$ aOR $=0.97,95 \% \mathrm{CI}=0.75-1.25$, respectively). Similarly, no associations were observed in female cancer survivors according to family history as well $(\mathrm{aOR}=0.76,95 \% \mathrm{CI}$ $=0.44-1.32$ for current smoking; $\mathrm{aOR}=1.11,95 \% \mathrm{CI}=0.94-1.31$ for current drinking; $\mathrm{aOR}=0.99,95 \% \mathrm{CI}=0.87-1.14$ for regular exercise; $\mathrm{OR}=0.99,95 \% \mathrm{CI}=0.85-1.16$ for obesity; $\mathrm{OR}=0.93$, $95 \% \mathrm{CI}=0.80-1.10$ for abdominal obesity) (Table 3).

\section{Clustering of health behaviors in cancer survivors}

When the association between FHCA and clustering of two health behaviors was estimated, male cancer survivors with FHCA were less likely to smoke and regularly exercised (OR = $0.76,95 \% \mathrm{CI}=0.58-1.00$ ) and were less likely to drink and regularly exercised ( $\mathrm{OR}=0.68,95 \% \mathrm{CI}=0.48-0.97)$. In female cancer survivors, when two health behaviors were combined and

B

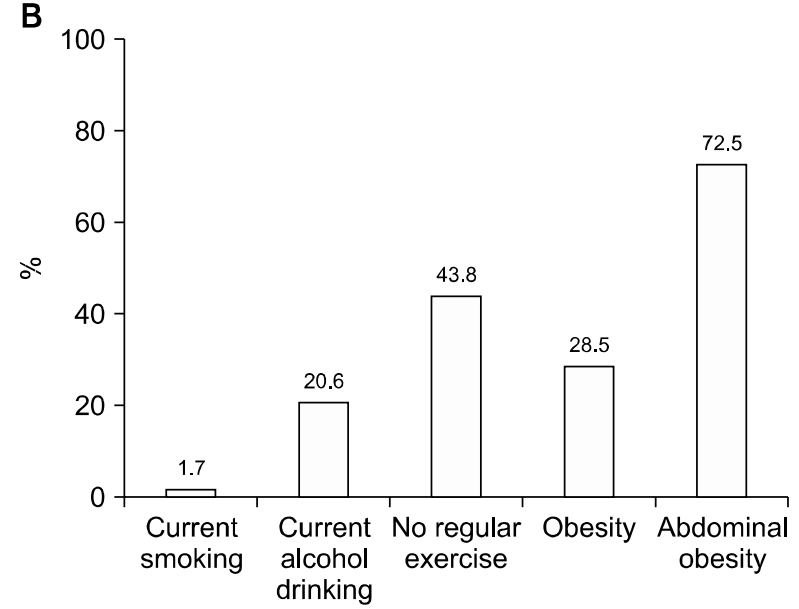

Figure 2. Prevalence of current smoking, drinking, no regular exercise, obesity, and abdominal obesity status in cancer survivors. (A) Prevalence in males with family history of cancer (FHCA); (B) Prevalence in females with FHCA. 
Table 2. Comparison of health behaviors according to FHCA in males and females (KoGES 2004-2013)

\begin{tabular}{|c|c|c|c|c|c|c|}
\hline \multirow{2}{*}{ Factor } & \multicolumn{3}{|c|}{ Male } & \multicolumn{3}{|c|}{ Female } \\
\hline & No FHCA & $\mathrm{FHCA}^{\mathrm{a}}$ & $P$-value ${ }^{\mathrm{b}}$ & No FHCA & $\mathrm{FHCA}^{\mathrm{a}}$ & $P$-value ${ }^{\mathrm{b}}$ \\
\hline \multicolumn{7}{|l|}{ Current smoking } \\
\hline No & $712(83.9)$ & $386(83.0)$ & & $2,446(98.1)$ & $1,402(98.6)$ & \\
\hline Yes & $136(16.0)$ & $79(17.0)$ & 0.656 & $46(1.9)$ & $19(1.3)$ & 0.231 \\
\hline \multicolumn{7}{|c|}{ Current alcohol drinking } \\
\hline No & $439(51.8)$ & $240(51.4)$ & & $1,994(79.8)$ & $1,114(78.5)$ & \\
\hline Yes & $409(48.2)$ & $227(48.6)$ & 0.896 & $504(20.2)$ & $305(21.5)$ & 0.327 \\
\hline \multicolumn{7}{|l|}{ Regular exercise } \\
\hline No & $318(37.5)$ & $157(33.6)$ & 0.161 & $1,100(44.0)$ & $621(43.6)$ & 0.804 \\
\hline Yes & $530(62.5)$ & $310(66.4)$ & & $1,399(56.0)$ & $803(56.4)$ & \\
\hline \multicolumn{7}{|l|}{ Obesity } \\
\hline No & $576(68.1)$ & $322(69.1)$ & & $1,772(71.0)$ & $1,020(71.9)$ & \\
\hline Yes & $269(31.8)$ & $144(30.9)$ & 0.728 & $724(29.0)$ & $399(28.1)$ & 0.555 \\
\hline \multicolumn{7}{|c|}{ Abdominal obesity } \\
\hline No & $471(56.2)$ & $271(58.8)$ & & $650(26.3)$ & $393(27.8)$ & \\
\hline Yes & $367(43.8)$ & $190(41.2)$ & 0.369 & $1,826(72.8)$ & $1,021(72.2)$ & 0.297 \\
\hline
\end{tabular}

Values are presented as number (\%). FHCA, family history of cancer; KoGES, Korean Genome and Epidemiology Study. ${ }^{a}$ FHCA included a family history of any type of cancer. ${ }^{\mathrm{b}} P$-values were determined using chi-square excluding the missing data.

Table 3. Association between FHCA and health behaviors among cancer survivors in multivariate logistic regression analysis

\begin{tabular}{|c|c|c|c|c|c|c|c|c|}
\hline \multirow{2}{*}{ Factor } & \multicolumn{4}{|c|}{ Male } & \multicolumn{4}{|c|}{ Female } \\
\hline & $\mathrm{OR}^{\mathrm{a}}$ & $P$-value & $\mathrm{aOR}^{\mathrm{b}}$ & $P$-value & $O R^{a}$ & $P$-value & $\mathrm{aOR}^{\mathrm{b}}$ & $P$-value \\
\hline Current smoking & $\begin{array}{c}1.07 \\
(0.79-1.45)\end{array}$ & 0.656 & $\begin{array}{c}1.04 \\
(0.75-1.44)\end{array}$ & 0.810 & $\begin{array}{c}0.72 \\
(0.42-1.24)\end{array}$ & 0.233 & $\begin{array}{c}0.76 \\
(0.44-1.32)\end{array}$ & 0.334 \\
\hline Current alcohol drinking & $\begin{array}{c}1.02 \\
(0.81-1.27)\end{array}$ & 0.896 & $\begin{array}{c}0.96 \\
(0.76-1.22)\end{array}$ & 0.766 & $\begin{array}{c}1.08 \\
(0.92-1.27)\end{array}$ & 0.328 & $\begin{array}{c}1.11 \\
(0.94-1.31)\end{array}$ & 0.204 \\
\hline No regular exercise & $\begin{array}{c}0.84 \\
(0.67-1.07)\end{array}$ & 0.161 & $\begin{array}{c}0.85 \\
(0.66-1.10)\end{array}$ & 0.221 & $\begin{array}{c}0.98 \\
(0.86-1.12)\end{array}$ & 0.804 & $\begin{array}{c}0.99 \\
(0.87-1.14)\end{array}$ & 0.949 \\
\hline Obesity & $\begin{array}{c}0.96 \\
(0.75-1.22)\end{array}$ & 0.728 & $\begin{array}{c}0.96 \\
(0.73-1.25)\end{array}$ & 0.736 & $\begin{array}{c}0.96 \\
(0.83-1.11)\end{array}$ & 0.556 & $\begin{array}{c}0.99 \\
(0.85-1.16)\end{array}$ & 0.925 \\
\hline Abdominal obesity & $\begin{array}{c}0.90 \\
(0.72-1.13)\end{array}$ & 0.369 & $\begin{array}{c}0.97 \\
(0.75-1.25)\end{array}$ & 0.810 & $\begin{array}{c}0.93 \\
(0.80-1.07)\end{array}$ & 0.297 & $\begin{array}{c}0.93 \\
(0.80-1.10)\end{array}$ & 0.405 \\
\hline
\end{tabular}

FHCA, family history of cancer; aOR, adjusted OR. ${ }^{a}$ Reference was cancer survivors who did not have any FHCA. ${ }^{b}$ Logistic regression analysis was adjusted for age, education, household income, employment condition, chronic disease, and self-rated health. In case of women, numbers of children and menopause were included.

the association with family history was estimated, there were no significant associations (data not shown).

\section{DISCUSSION}

The aim of this study was to compare health behaviors, including current smoking, current alcohol drinking, regular exercise, obesity, and abdominal obesity, among cancer survivors with or without FHCA to identify possible reasons of better survival in cancer patients. We identified that there were no significant differences in health behaviors according to FHCA in cancer survivors. Although there were no differences according to family history, the prevalence of unhealthy behaviors in cancer survivors was high. More than $40 \%$ of male cancer survivors drank alcohol and had abdominal obesity. More than $30 \%$ of them did not exercise regularly and were obese, and $16 \%$ smoked. In female cancer survivors, $43 \%$ did not exercise regularly, and about $20 \%$ drank alcohol or were obese. Most especially, more than $70 \%$ of female survivors had abdominal obesity.

With respect to FHCA and health behaviors, most studies targeted the general population. An earlier study found that female relatives of patients with breast cancer were more likely to undergo breast cancer screening than those without breast cancer, and male relatives of patients with prostate cancer were 
more likely to undergo prostate cancer screening than those without prostate cancer. ${ }^{24.25}$ Similarly, another study found that FHCA was related to higher probability of cancer screening. However, FHCA was not related to other lifestyle behaviors, such as smoking, physical activity, alcohol consumption, BMI, or eating habits. Even family history was negatively associated with these behaviors in some subgroups. ${ }^{26}$ In addition, previous studies reported that there were no associations between lifestyle factors, including smoking, drinking, physical exercise, and dietary habits, and FHCA in first-degree relatives with gastric, breast, colorectal, and lung cancer. ${ }^{26,27}$ Studies conducted in Korea showed conflicting results. In a study that targeted Korean females, women with FHCA presented poorer health behaviors-more likely to smoke and have experience of passive smoking and less likely to exercise regularly-than women without FHCA. ${ }^{28}$ However, another study reported that relatives of gastric cancer patients did not show significant differences in dietary habits and smoking compared with control groups, despite having significantly higher gastric cancer screening experience. ${ }^{29}$

Based on previous results, it could be suggested that people with FHCA were more likely to receive cancer screening than people without FHCA; however, in the aspect of lifestyle behaviors, there was no association with FHCA. Our results were similar with previous studies in terms of lifestyle behaviors, adding evidence that FHCA was not associated with health behaviors. One major difference between previous studies and ours was that we recruited cancer survivors for our study population.

This study was based on the hypothesis that there is an association between health behaviors and FHCA in cancer survivors, which may explain better prognosis or survival in cancer patients with FHCA compared with those without FHCA. ${ }^{12-15}$ However, the non-differences between the two groups in our study did not support the association between FHCA and survival. ${ }^{16-18}$ Previous studies that compared health behaviors in cancer survivors with the general population showed more healthy behaviors, including less current drinking, smoking, and physical inactivity. ${ }^{30}$ Thus, the diagnosis of cancer may have already changed the lifestyle behaviors of cancer survivors, ${ }^{31}$ and the effect of FHCA after the diagnosis of cancer would not be significant. In this study, because people without cancer were not included in the analysis, it was impossible to compare their health behaviors with those of cancer survivors directly, despite the prevalence of current smoking, drinking, and physical inactivity being much lower than previous studies conducted in the Korean population. ${ }^{30}$ Thus, it could be suggested that the impacts of cancer diagnosis were strong enough to change health behaviors and offset the impacts of FHCA.

To the best of our knowledge, this study was the first to examine the association between health behaviors and FHCA in cancer survivors. This means health providers would be more aware of preventive recommendation of cancer survivors regardless of FHCA, and more studies need to be performed to investigate the underlying effect of FHCA on cancer prognosis.

Although we have examined valuable information, several limitations were considered for the interpretation of the results. First, some questionnaires of the KoGES data had been changed during the 2004 to 2013 period. It may influence the accuracy of the information. Second, HEXA data were collected at several different centers and included individuals aged over 40 years, so the study populations might be heterogeneous according to recruitment center; however, we did not adjust for the center. In addition, the participants were health examinees visiting health examination centers located in metropolitan areas or major cities. Thus, they may have different social, economic, and health status compared with the general population, limiting generalization. In addition, we defined cancer survivors as those who responded yes to the question "Have you ever been diagnosed with cancer in the past?" Moreover, survival bias should also be considered because we did not include those who were admitted to the hospital or died. All of the information regarding both FHCA and lifestyle behaviors were from questionnaires and may not be valid due to recall bias or information bias. However, the potential bias related to survival, recall, or information bias was non-differential; thus, the effect on the results would be minimal. In addition, the number of cancer survivors included in the study was not enough to determine the association of FHCA according to cancer types and health behaviors. Due to the above limitation, we suggest that further research is necessary to examine the association between FHCA and health behaviors in cancer survivors, with more representative samples and larger sample size.

In conclusion, health behaviors of cancer survivors were not different according to FHCA. However, although health behaviors may be modifiable, the prevalence of unhealthy behaviors was still high. Thus, these kinds of health behaviors need to be assessed in cancer survivors irrespective of FHCA. In addition, more studies need to be conducted to identify the underlying mechanisms between FHCA and prognosis in cancer survivors. 


\section{ACKNOWLEDGMENTS}

This research was supported by Basic Science Research Program through the National Research Foundation of Korea (NRF) funded by the Ministry of Science, ICT and Future Planning (NRF-2016R1C1B1013621).

\section{CONFLICTS OF INTEREST}

No potential conflicts of interest were disclosed.

\section{REFERENCES}

1. Jung KW, Won YJ, Oh CM, Kong HJ, Lee DH, Lee KH. Cancer statistics in Korea: incidence, mortality, survival, and prevalence in 2014. Cancer Res Treat 2017;49:292-305.

2. Gallicchio L, Kalesan B, Hoffman SC, Helzlsouer KJ. Non-cancer adverse health conditions and perceived health and function among cancer survivors participating in a community-based cohort study in Washington County, Maryland. J Cancer Surviv 2008:2:12-9.

3. Eakin EG, Youlden DR, Baade PD, Lawler SP, Reeves MM, Heyworth JS, et al. Health status of long-term cancer survivors: results from an Australian population-based sample. Cancer Epidemiol Biomarkers Prev 2006;15:1969-76.

4. Yabroff KR, Lawrence WF, Clauser S, Davis WW, Brown ML. Burden of illness in cancer survivors: findings from a population-based national sample. J Natl Cancer Inst 2004:96: 1322-30.

5. Demark-Wahnefried W, Jones LW. Promoting a healthy lifestyle among cancer survivors. Hematol Oncol Clin North Am 2008:22:319-42, viii.

6. Demark-Wahnefried W, Pinto BM, Gritz ER. Promoting health and physical function among cancer survivors: potential for prevention and questions that remain. J Clin Oncol 2006;24: 5125-31.

7. Ganz PA. Late effects of cancer and its treatment. Semin Oncol Nurs 2001;17:241-8.

8. Parsons A, Daley A, Begh R, Aveyard P. Influence of smoking cessation after diagnosis of early stage lung cancer on prognosis: systematic review of observational studies with meta-analysis. BM) 2010;340:b5569.

9. Eakin EG, Youlden DR, Baade PD, Lawler SP, Reeves MM, Heyworth JS, et al. Health behaviors of cancer survivors: data from an Australian population-based survey. Cancer Causes Control 2007; 18:881-94.

10. Coups EJ, Ostroff JS. A population-based estimate of the prevalence of behavioral risk factors among adult cancer survivors and noncancer controls. Prev Med 2005:40:702-11.

11. Bellizzi KM, Rowland JH, Jeffery DD, McNeel T. Health behaviors of cancer survivors: examining opportunities for cancer control intervention. J Clin Oncol 2005;23:8884-93.

12. Getz KR, Rozek LS, Peterson LA, Bellile EL, Taylor JMG, Wolf GT, et al. Family history of cancer and head and neck cancer survival. Laryngoscope 2017;127:1816-20.

13. Han MA, Oh MG, Choi IJ, Park SR, Ryu KW, Nam BH, et al.
Association of family history with cancer recurrence and survival in patients with gastric cancer. J Clin Oncol 2012;30:701-8.

14. Birgisson H, Ghanipour A, Smedh K, Påhlman L, Glimelius B. The correlation between a family history of colorectal cancer and survival of patients with colorectal cancer. Fam Cancer 2009;8: 555-61.

15. Chan JA, Meyerhardt JA, Niedzwiecki D, Hollis D, Saltz LB, Mayer $\mathrm{RJ}$, et al. Association of family history with cancer recurrence and survival among patients with stage III colon cancer. JAMA 2008:299:2515-23.

16. Melvin JC, Wulaningsih W, Hana Z, Purushotham AD, Pinder SE, Fentiman I, et al. Family history of breast cancer and its association with disease severity and mortality. Cancer Med 2016; 5:942-9.

17. Thalib L, Wedrén S, Granath F, Adami HO, Rydh B, Magnusson C, et al. Breast cancer prognosis in relation to family history of breast and ovarian cancer. Br J Cancer 2004:90:1378-81.

18. Eccles BK, Copson ER, Cutress RI, Maishman T, Altman DG, Simmonds P, et al. Family history and outcome of young patients with breast cancer in the UK (POSH study). Br J Surg 2015; 102:924-35.

19. Kash KM, Holland JC, Halper MS, Miller DG. Psychological distress and surveillance behaviors of women with a family history of breast cancer. J Natl Cancer Inst 1992;84:24-30.

20. Kim Y, Han BG; KoGES Group. Cohort profile: the Korean genome and epidemiology study (KoGES) consortium. Int J Epidemiol 2017; $46:$ e20.

21. Health Examinees Study Group. The Health Examinees (HEXA) study: rationale, study design and baseline characteristics. Asian Pac J Cancer Prev 2015;16:1591-7.

22. Jee SH, Yun JE, Park EJ, Cho ER, Park IS, Sull JW, et al. Body mass index and cancer risk in Korean men and women. Int J Cancer 2008; 123:1892-6.

23. Lear SA, James PT, Ko GT, Kumanyika S. Appropriateness of waist circumference and waist-to-hip ratio cutoffs for different ethnic groups. Eur J Clin Nutr 2010;64:42-61.

24. Jacobsen PB, Lamonde LA, Honour M, Kash K, Hudson PB, Pow-Sang J. Relation of family history of prostate cancer to perceived vulnerability and screening behavior. Psychooncology 2004:13:80-5.

25. Lerman C, Rimer B, Trock B, Balshem A, Engstrom PF. Factors associated with repeat adherence to breast cancer screening. Prev Med 1990;19:279-90.

26. Bostean G, Crespi CM, McCarthy WJ. Associations among family history of cancer, cancer screening and lifestyle behaviors: a population-based study. Cancer Causes Control 2013;24:1491-503.

27. Huang XE, Hirose $\mathrm{K}$, Wakai $\mathrm{K}$, Matsuo $\mathrm{K}$, Ito H, Xiang J, et al. Comparison of lifestyle risk factors by family history for gastric, breast, lung and colorectal cancer. Asian Pac J Cancer Prev 2004:5:419-27.

28. Ham Y, Oh HY, Seo SS, Kim MK. Association between health behaviors and a family history of cancer among Korean women. Cancer Res Treat 2016;48:806-14.

29. Kang JM, Shin DW, Kwon YM, Park SM, Park MS, Park JH, et al. Stomach cancer screening and preventive behaviors in relatives of gastric cancer patients. World J Gastroenterol 2011;17:3518-25.

30. Park B, Kong SY, Kim J, Kim Y, Park IH, Jung SY, et al. Health behaviors of cancer survivors in nationwide cross-sectional survey in Korea: higher alcohol drinking, lower smoking, and physical 
inactivity pattern in survivors with higher household income. Medicine (Baltimore) 2015;94:e1214.

31. McBride CM, Emmons KM, Lipkus IM. Understanding the poten- tial of teachable moments: the case of smoking cessation. Health Educ Res 2003;18:156-70. 